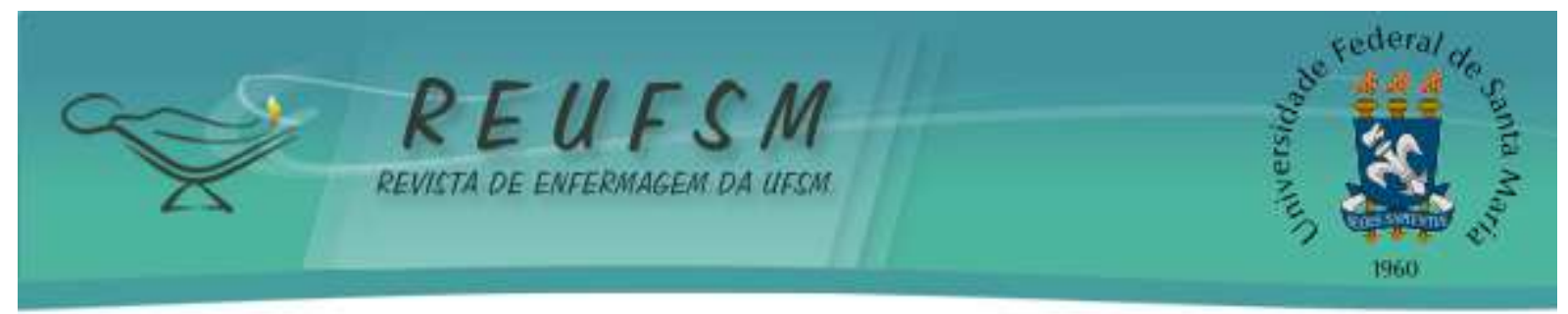

\title{
PERCEPÇÃO DE GRADUANDOS DE ENFERMAGEM SOBRE A APRENDIZAGEM BASEADA EM PROBLEMAS*
}

\section{PERCEPTION OF NURSING STUDENTS ON PROBLEM-BASED LEARNING COMPRENSIÓN DE GRADUANDOS DE ENFERMERÍA SOBRE EL APRENDIZAJE BASADO EN PROBLEMAS}

\author{
Miriam Fernanda Sanches Alarcon ${ }^{1}$ \\ Maria José Quina Galdino ${ }^{2}$ \\ Júlia Trevisan Martins ${ }^{3}$ \\ Kelly Holanda Prezotto 4 \\ Ricardo Shoiti Komatsu ${ }^{5}$
}

Doi: $10.5902 / 2179769227978$

RESUMO: Objetivo: revelar a percepção de graduandos sobre o método de Aprendizagem Baseada em Problemas. Método: estudo qualitativo realizado com 16 graduandos de enfermagem de uma universidade pública da Região Sul do Brasil. Os dados foram coletados por entrevistas individuais e submetidos à Análise de Conteúdo. Resultados: identificaram-se três categorias: despertando, pesquisando e trocando experiência; facilitando o relacionamento interpessoal e relação teoria-prática e falta de tempo para desenvolver o método. Os estudantes revelaram que o método de aprendizagem baseada em problemas é um estímulo positivo, pois facilita a relação profícua entre estudantes e tutores, correlacionando prática e teoria, porém, uma das maiores dificuldades indicada nesse método é a falta de tempo para desenvolvê-lo. Conclusão: os estudantes perceberam o método como uma estratégia importante e efetiva nos processos de ensino e aprendizagem.

Descritores: Aprendizagem baseada em problemas; Educação em enfermagem; Estudantes de enfermagem; Percepção do estudante; Processos de ensino- aprendizagem

ABSTRACT: Aim: to reveal the students' perception about the problem-based learning. Method: this is a qualitative study carried out with 16 nursing undergraduates from a public university in the Southern Region of Brazil. Data were collected through individual interviews and submitted to content analysis. Results: three categories were identified: Awakening, researching and exchanging experience; Facilitating interpersonal relationships and the relation between theory and practice and lack of time to develop method. The students revealed that the problem-based learning method is a positive stimulus, because it enables the

\footnotetext{
*Extraído da dissertação de mestrado "Aprendizagem Baseada em Problemas: Uma proposta para o estágio curricular supervisionado na graduação em enfermagem". Mestrado em "Ensino em Saúde" da Faculdade de Medicina de Marília - FAMEMA.

${ }^{1}$ Enfermeira. Doutoranda do Programa de Pós-Graduação em Enfermagem da Universidade Estadual Paulista "Júlio de Mesquita Filho". Botucatu, São Paulo, Brasil. E-mail: miriam@uenp.edu.br

${ }^{2}$ Enfermeira. Doutoranda do Programa de Pós-Graduação em Enfermagem da Universidade Estadual de Maringá. Maringá, Paraná, Brasil. E-mail: mariagaldino@uenp.edu.br

${ }^{3}$ Enfermeira. Doutora em Enfermagem. Universidade Estadual de Londrina. Londrina, Paraná, Brasil. E-mail: jtmartins@uel.br

${ }^{4}$ Enfermeira. Doutoranda do Programa de Pós-Graduação em Enfermagem da Universidade Estadual de Maringá. Maringá, Paraná, Brasil. E-mail: kelly.prezotto@uenp.edu.br

${ }^{5}$ Médico. Doutor em Educação. Faculdade de Medicina de Marília - FAMEMA. Marília, São Paulo, Brasil. Email: komatsu@terra.com.br
} 


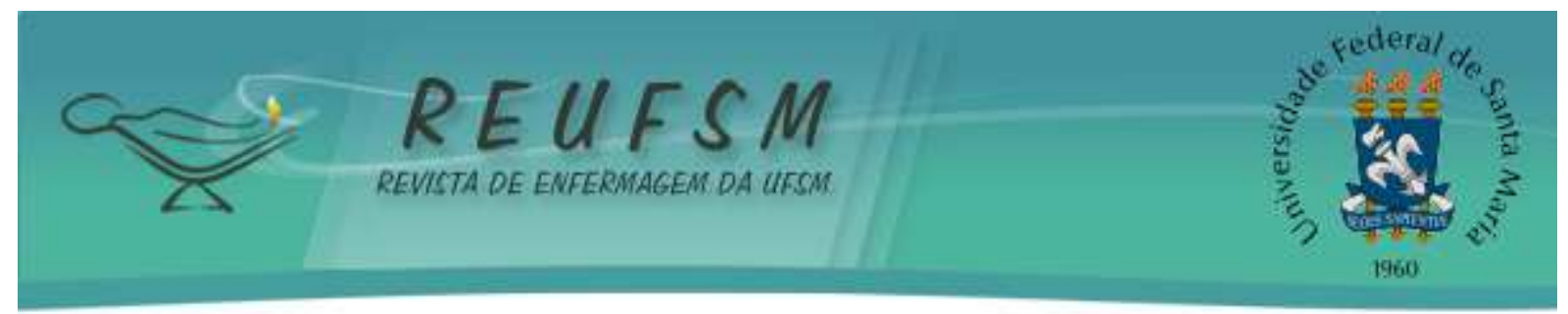

profitable relationship between students and tutors, correlating practice-theory. However, one of the greatest difficulties indicated about this method is the lack of time to develop it. Conclusion: the students perceived the method as an important and effective strategy in the teaching and learning processes.

Descriptors: Problem-based learning; Nursing education; Nursing students; Perceptions of the student; Teaching- learning processes

RESUMEN: Objetivo: revelar la comprensión de los graduandos sobre el método de aprendizaje basado en problemas. Método: estudio cualitativo realizado con 16 graduandos de enfermería de una universidad pública de la Región Sur de Brasil. Los datos fueron recolectados por medio de entrevistas individuales y analizados por análisis de contenido. Resultados: se identificó tres categorías: despertando, investigando e intercambiando experiencia, facilitando la relación interpersonal y la relación entre teoría-práctica y la falta de tiempo para desarrollar el método. Los estudiantes revelaron que el método de aprendizaje basado en problemas es un estímulo positivo, porque proporciona una relación productiva entre estudiantes y tutores, correlacionando la práctica y teoría, pero una de las mayores dificultades del método es la falta de tiempo para desarrollarlo. Conclusión: los estudiantes comprendieron el método como una estrategia importante y efectiva en los procesos de enseñanza y aprendizaje.

Descriptores: Aprendizaje basado en problemas; Educación en enfermería; Estudiantes de enfermería; Percepción del estudiante; Procesos de enseñanza y aprendizaje

\section{INTRODUÇÃO}

A formação de profissionais, tanto na área da saúde como em qualquer outra, vem se modificando para atender a sociedade nas suas reais necessidades. As implementações de novas metodologias de ensino são essenciais e, os educadores devem buscar novos paradigmas visando à formação para estas realidades.

No campo da enfermagem, os conhecimentos adquiridos devem ir além do ensino técnico-científico, pois há a necessidade de que seus profissionais transformem suas práticas e a própria organização laboral, buscando uma estrutura organizacional em que seja possível acolher e prestar cuidado integral às pessoas e, por sua vez, a toda comunidade. ${ }^{1-2}$

A Lei de Diretrizes e Bases da Educação Nacional (LDB) e as Diretrizes Curriculares Nacionais (DCN) do curso de graduação em Enfermagem, no qual os estudantes estão inseridos, determinam, como perfil do egresso, uma formação: generalista, humanista, crítica e reflexiva, sugerindo ainda a utilização de novas práticas pedagógicas que enfatizem a atuação do enfermeiro com senso de responsabilidade social e compromisso com a cidadania para promoção da saúde integral do ser humano. ${ }^{3}$

Entretanto, um número considerável de estudantes vivencia em seu cotidiano acadêmico o método tradicional, ou seja, um modelo pedagógico sustentado pela retenção de informações, por 


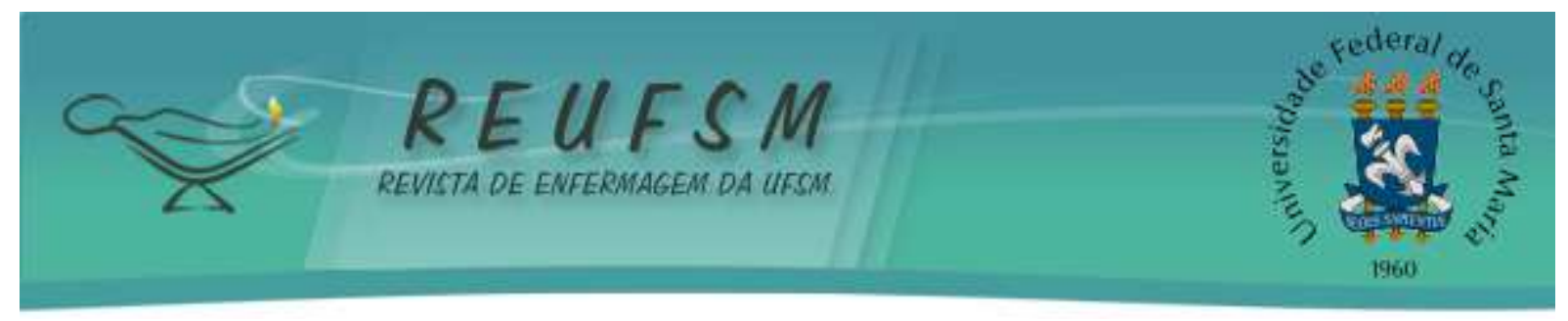

sistemas rígidos com disciplinas isoladas e avaliações com exercícios de aprendizagem por memorização, o que implica, consequentemente, em atores de aprendizagem passivos que apresentam dificuldades em realizar questionamentos críticos baseados na realidade profissional.

Para alcançar as metas propostas nas DCN, as instituições de ensino superior devem buscar, por meio de seus currículos, qualificar os novos enfermeiros para torná-los capazes, seguros, dinâmicos, criativos e que busquem, incessantemente, novos conhecimentos e atualizações com a finalidade de atender as demandas do sistema de saúde e da população. Para tanto, é preciso romper com os modelos tradicionais de ensino que ainda estão presentes na grande maioria dos cursos de graduação em enfermagem; em que o conteúdo é valorizado, fragmentado e o biologicismo predomina. ${ }^{4}$

Dentre os modelos considerados inovadores e com resultados significativos para a formação de profissionais capazes de atuar de acordo com a realidade social e em consonância com o Sistema Único de Saúde (SUS), destacam-se as metodologias da Problematização e Aprendizagem Baseada em Problemas (ABP), as quais, embora distintas, possuem várias semelhanças, pois ambas, buscam romper com os métodos tradicionais de ensino e aprendizagem. ${ }^{5}$

No presente estudo, os pressupostos adotados foram os da ABP. Este método é considerado como uma estratégia didática, na qual utilizam-se problemas reais da sociedade como parte do aprendizado, buscando soluções para o aperfeiçoamento do conhecimento e, estimulando, assim, o pensamento crítico. Estudiosos do método afirmam que sua aplicação gera melhora no conhecimento do conteúdo, no desenvolvimento da educação e na aprendizagem autodirigida. ${ }^{6}$ Tal método surgiu na década de 1930 nos Estados Unidos, a partir de uma discussão em grupo na Harvard Business School, e, posteriormente, na década de 1960, foi reformulado pela Escola de Medicina de McMaster, no Canadá. ${ }^{7}$

$\mathrm{Na}$ perspectiva de ensino e aprendizagem, os estudos na metodologia ABP são direcionados de forma a gerar questionamentos que serão discutidos e solucionados pelo grupo, obtendo troca de experiências e valorização do papel ativo do estudante, o qual deixa de ser um mero receptor de informações. Além disso, o papel do professor nessa proposta é o de tutor, pelo fato de ser o estimulador das discussões. ${ }^{8}$

A ferramenta essencial do tutor, no método ABP, são os denominados problemas de papel, que funcionam como a mola propulsora no estímulo ao estudante na busca de conhecimentos antecipados para alcançar os resultados propostos. Os problemas de papel 


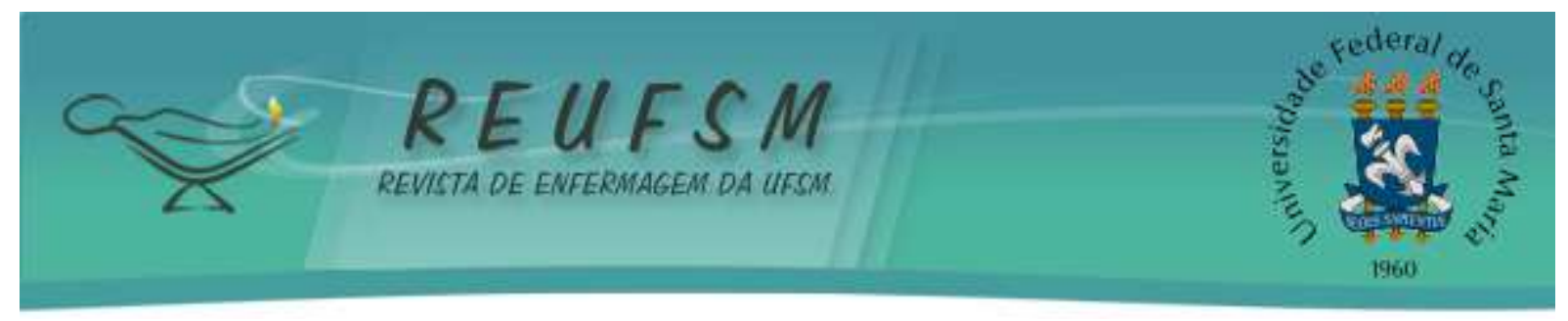

devem ser: autênticos, interessantes, formulados de forma a levar a uma discussão adequada, devendo estimular o estudo dirigido e a reflexão do conhecimento. ${ }^{9}$

A ABP vem sendo utilizada por várias instituições de ensino, principalmente em cursos da área de Saúde. No exterior, destaca-se a Universidade de Maastrich, na Holanda; de Harvard e Cornell, nos EUA; no Brasil, a Faculdade de Medicina de Marília, a Universidade Estadual de Londrina (UEL) e a Universidade São Francisco adotaram o método com sucesso. ${ }^{10}$

Há ainda experiências pontuais já reconhecidas pelo êxito, como, por exemplo, a desenvolvida em uma disciplina (Hematologia) na Faculdade de medicina da UFRJ e outra, ainda em desenvolvimento, na formação pedagógica de mestrandos de Medicina e de Odontologia da mesma Universidade. ${ }^{10}$

O estudo demonstrou que a ABP se constitui em um método de ensino e aprendizagem que contribui de forma eficaz para o raciocínio lógico e julgamento clínico entre os estudantes de enfermagem, formando profissionais mais aptos a atuar no sistema de saúde em seus diferentes níveis de atenção. ${ }^{11}$

Ante o exposto, acredita-se que realizar investigações sobre as experiências vivenciadas por graduandos de enfermagem, frente a uma nova metodologia de ensino e aprendizado, pode configurar-se em um processo de conhecimento que reverta as ações para um atendimento das necessidades reais das pessoas e da sociedade, estando de acordo com o preconizado pelo SUS.

Por ciência da necessidade de mudanças curriculares que idealizam egressos da graduação na área da saúde, estudos comprovaram que métodos ativos de ensino são necessários para o alcance de melhorias na aprendizagem. ${ }^{12-13}$

Diante das considerações, questionou-se: qual a percepção dos estudantes sobre o método de ensino ABP como estratégia de ensino e aprendizagem desenvolvida em um curso de graduação em enfermagem com currículo tradicional? Portanto, o objetivo foi revelar a percepção de graduandos de enfermagem sobre o método de Aprendizagem Baseada em Problemas.

\section{MÉTODO}

Trata-se de um estudo descritivo com abordagem qualitativa realizado com estudantes do curso de graduação em enfermagem de uma universidade pública da Região Sul do Brasil, que utiliza o currículo tradicional desde 2001. 


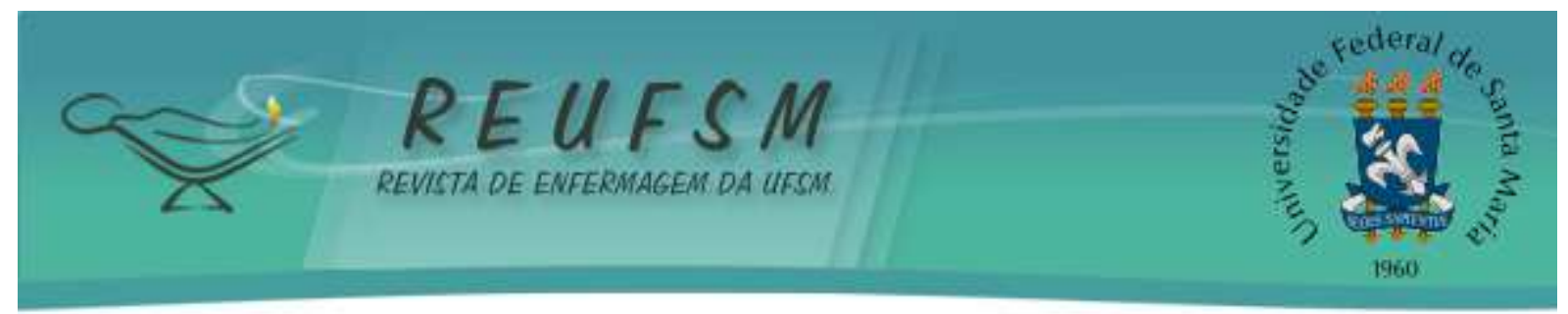

Os participantes encontravam-se matriculados no $6^{\circ}$ semestre do curso, na disciplina de Alta Complexidade - Unidade de Terapia Intensiva (UTI), apresentando um total de 30 estudantes. Adotou-se como critérios de inclusão ser estudante regular do curso e, como critério de exclusão, estudantes que não compareceram no dia da entrevista.

Baseado nesses critérios, 16 estudantes tornaram-se participantes da investigação. No período de agosto a novembro de 2012, os graduandos frequentaram 24 sessões de tutoria com duração de 105 horas, sendo essas teóricas. As sessões foram realizadas por um docente da disciplina, o qual construiu os problemas de papel, consistindo na apresentação e discussão dos 12 passos da APB: 1. Apresentação do problema e formulação de questionamentos relacionados a sua descrição; 2. Resumo dos dados relevantes do problema; 3. Identificação de prioridades nas perspectivas biológica, psicológica e social; 4. Levantamento do conhecimento atual acerca do problema; 5. Formulação de hipóteses; 6. Identificação do conhecimento adicional sobre a temática em estudo; 7. Identificação de recursos de aprendizagem apropriados para a resolução do problema, tais como: busca de artigos em periódicos científicos ou nas bases de dados, entrevistas com professores, profissionais ou usuários, vídeos, laboratório, entre outros; 8. Procura por novos conhecimentos; 9. Síntese das evidências e conhecimentos sobre o assunto em questão; 10. Repetição dos passos anteriores, caso haja necessidade; 11. Reconhecimento dos itens relevantes identificados e que não foram satisfatoriamente discutidos ou explorados; 12. Síntese e avaliação do conhecimento adquirido. ${ }^{14}$

Quanto às sessões tutoriais, destaca-se que a professora-pesquisadora era a docente responsável pela disciplina de UTI, a qual realizou capacitação para tutoria na Faculdade de Medicina de Marília, instituição que utiliza ABP desde 1997. A ABP foi implementada segundo os princípios norteadores da metodologia ao longo de 24 encontros, ocorridos durante 12 semanas, contendo 06 problemas de papel que atingiram a totalidade do currículo proposto. Cada sessão de tutoria tinha a duração de duas horas, com dois encontros semanais.

Cada tema compreendia a abertura do problema na terça-feira e discussões na quintafeira, próxima terça-feira e quinta-feira novamente, quando ocorria, nessa última, não só discussão, mas, também, o fechamento. A previsão, dessa forma, era de 4 sessões de tutoria para o desenvolvimento de cada problema, permitindo a exploração dos temas propostos na programação ("Plano de Ensino") da referida disciplina de UTI. 


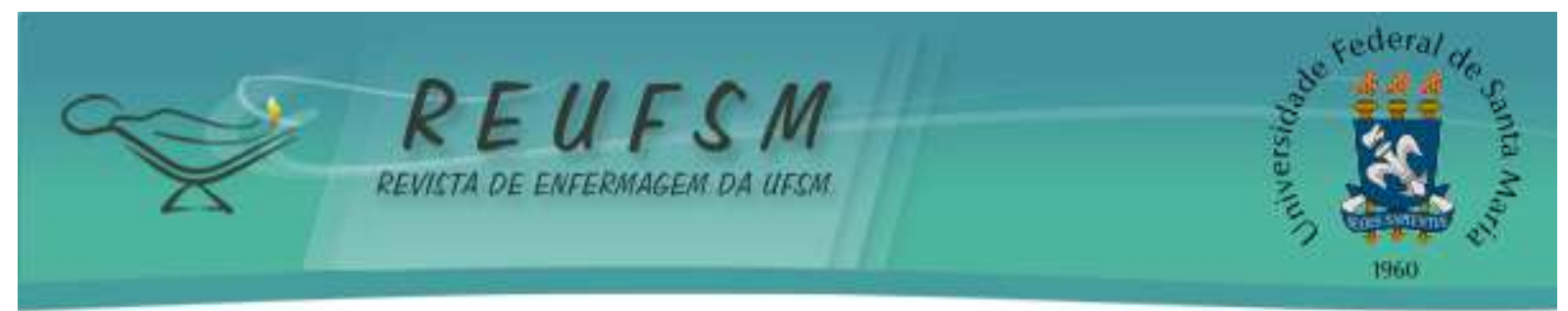

Após o término das sessões tutoriais, realizou-se entrevista semiestruturada individual em sala reservada na própria universidade, entre os meses de novembro e dezembro de 2012. Utilizou-se, durante a entrevista, um roteiro semiestruturado, constituído de duas partes: a primeira com questões referentes à caracterização dos entrevistados (idade, sexo e estado civil) e a segunda referente à seguinte questão norteadora: qual a sua percepção sobre o método de ensino e aprendizagem ABP, utilizado na disciplina de Alta Complexidade - UTI? As entrevistas foram gravadas em mídia digital, tiveram duração média de vinte minutos e foram transcritas na íntegra no mesmo dia, logo após o seu término. Embora a saturação de dados (reincidência de informações) tenha ocorrido na décima primeira entrevista, optou-se por entrevistar os 16 participantes das sessões tutoriais. As variáveis analisadas foram referentes às relações interpessoais em sala de aula; pensamento crítico e reflexivo; tempo; espaço; e acesso às fontes de informação.

Para analisar os dados, os conteúdos das entrevistas foram submetidos à análise de conteúdo na modalidade temática e seguiu as fases de pré-análise, exploração do material, tratamento dos resultados e interpretação. $\mathrm{Na}$ fase de pré-análise foram realizadas leituras das falas, com a finalidade de identificar os pontos relevantes para o objetivo. $\mathrm{Na}$ fase de exploração do material realizou-se a codificação, em que foram atribuídos códigos aos núcleos de sentido, que representaram o conteúdo expresso nas falas e que foram agregados em unidades. Durante a última fase foi realizada a categorização, que se configurou na classificação dos elementos, segundo suas semelhanças, e, por diferenciação, com o posterior reagrupamento em função de características comuns. ${ }^{15}$

A pesquisa levou em conta os preceitos éticos propostos na Resolução 466/2012 e foi aprovado pelo Comitê de Ética em Pesquisa com Seres Humanos da Faculdade de Medicina de Marília por meio do parecer 176/2012. Todos consentiram sua participação após assinatura do Termo de Consentimento Livre e Esclarecido. Para preservação do anonimato foram utilizados os códigos entre E1 e E16.

\section{RESULTADOS}

Dentre os 16 estudantes de enfermagem que fizeram parte do presente estudo, 13 são do sexo feminino e três do sexo masculino, com idades entre 19 e 21 anos e todos solteiros. 


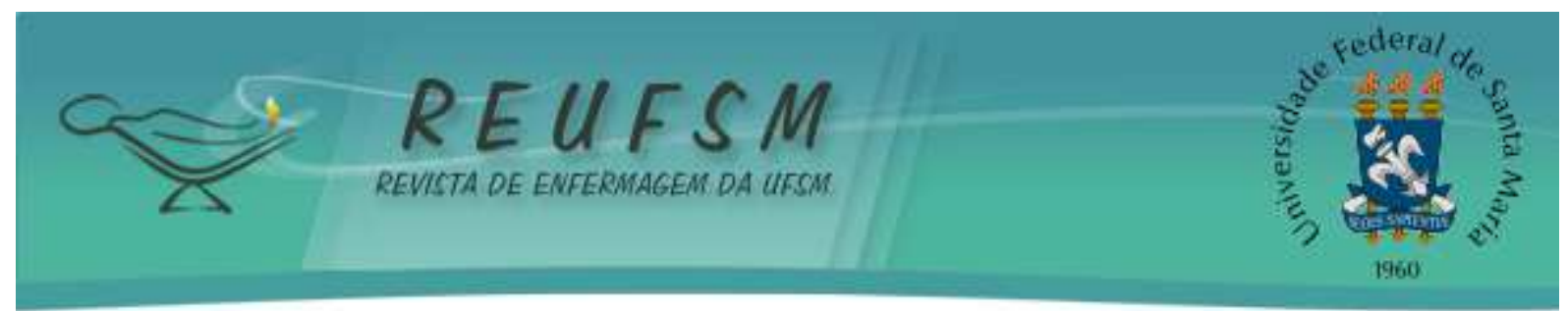

A partir da análise de conteúdo emergiram três categorias que expressam a percepção dos estudantes de enfermagem com relação ao método do ABP utilizado na disciplina de Alta Complexidade - UTI e estão descritas a seguir:

\section{Despertando, pesquisando e trocando experiência}

As falas dos entrevistados demonstraram que o método $\mathrm{ABP}$ é um estímulo positivo para que os mesmos busquem pelo próprio conhecimento e que, por consequência, amplia a aprendizagem dos assuntos, visto que podem trocar as experiências. As falas também evidenciaram a importância deste método para os estudantes como uma forma de não centralizar o ensino-aprendizagem no modelo tradicional, no qual o professor é o que ministra o máximo de conteúdos possíveis e os estudantes ouvem isso como verdade absoluta. É o que revela os seguintes depoimentos:

A ABP é um despertar positivo para a busca do nosso aprendizado e ajuda muito a termos um conhecimento amplo dos assuntos e dos temas, pois somos nós, com estímulo do professor, que buscamos esse aprendizado. [...] Na minha percepção, melhora a aprendizagem, pois julgo que é melhor discutir um problema do que ficar ouvindo sobre ele, como é realizado pelo método tradicional de ensino. [...] É uma troca de experiência entre todos. (E2)

Nós estudantes que realizamos a busca das informações e somos estimulados a todo momento pelo tutor a ser responsáveis pelo nosso aprendizado. (E6)

No método ABP nos tornamos responsáveis pelo assunto a ser estudado e isso traz uma melhor aprendizagem deste conteúdo. O professor não é aquele que só fala e fala e vai embora. É mais do que isso! É aquele que estimula a gente a se interessar pelo conhecimento. (E7)

Outros participantes referiram o método ABP como um ponto positivo ao despertar o interesse pela pesquisa, uma vez que a estratégia mais utilizada neste modelo de ensinoaprendizagem está pautada na investigação. O que pode ser evidenciado nas falas a seguir:

$O$ método ABP estimula a pesquisar todos os dias e, assim, a gente vai vendo a importância das pesquisas, quer seja buscando aprimorar nosso conhecimento por determinado assunto ou pesquisando sobre algum problema que a gente identifica. (E1)

Eu não estava acostumado a realizar pesquisas sobre o que era dado em sala de aula, pois eu tinha apostila pronta com o conteúdo, agora com o método ABP preciso buscar conhecimento e isso estimula mais a gente ainda. (E14) 


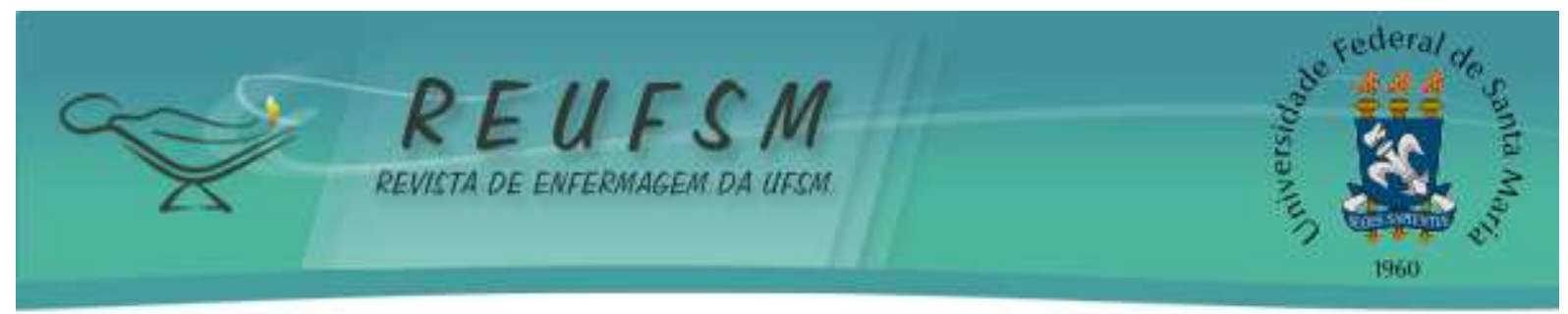

Alguns relatam a importância do método para o despertar da pesquisa:

Na minha percepção, o método ABP é muito importante para despertar para a pesquisa. Depois de eu conhecer o método ABP sei que quero ser um enfermeiro pesquisador. (E5)

Estimula o espírito de pesquisador na gente. (E12)

Eu esperava sempre os professores a trazer o conteúdo, agora eu preciso buscar o conteúdo por meio de pesquisa e isso estimula a gente, mostrando que somos capazes. (E2)

Conforme as expressões dos estudantes, tais afirmativas da categoria demonstraram características positivas do método ABP para a busca do próprio conhecimento. Ao indagar o estudante sobre a relação interpessoal, as principais afirmações foram agrupadas na categoria a seguir:

\section{Facilitando o relacionamento interpessoal e relação teoria e prática}

Ainda o método ABP foi identificado pelos estudantes como facilitador de uma relação profícua entre estudantes e tutores, isso é, as falas indicam a importância de um relacionamento interpessoal para aprimorar o ensino-aprendizagem, conforme revelam os depoimentos:

O professor no método ABP é um tutor e é muito legal, pois facilita demais o nosso relacionamento, não é que a gente não respeite, mas por ele ser um facilitador, facilita tudo, em especial, o relacionamento... e a gente fica estimulado a aprender mais. (E6)

$O$ relacionamento com o tutor é mais próximo, até pelo fato de ser poucos estudantes e o tutor da mais abertura para as discussões. (E16)

Para mim o que mais me chamou a atenção no método de ensino ABP foi que eu perdi o medo de tutor, eu fico muito à vontade para me dirigir a ele e eu fico até estimulado a perguntar as minhas dúvidas. (E8)

Percebeu-se que o método em questão é um facilitador para a relação da prática com a teoria. Esse fato está diretamente, relacionado com a técnica da $\mathrm{ABP}$, na qual é levantado um problema oriundo da prática para que sejam investigadas possíveis soluções relacionando-as com a teoria. As falas a seguir denotam esse entendimento:

Para mim o método ABP é sem sombra de dúvida um facilitador para nós entendermos melhor a teoria e sua relação com a prática. (E7)

Com o método ABP nunca mais vou esquecer a teoria e de sua relação com a prática da enfermagem. (E13)

Agora consigo entender essa relação da teoria com a prática, agora enxergo essa aproximação. (E4) 


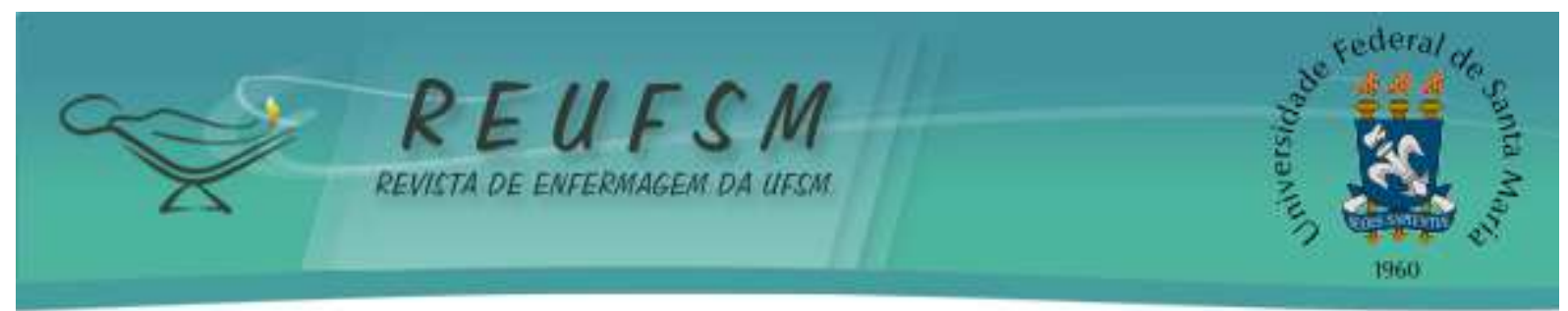

As expressões dos estudantes denotam a facilidade do método ABP no relacionamento interpessoal e uma maior relação da teoria com a prática. Ao questionar o estudante sobre a dificuldade do método, as principais afirmações foram agrupadas na categoria a seguir:

\section{A falta de tempo para desenvolver o método}

Pelas falas dos estudantes desvela-se que uma das dificuldades para empregar o método do ABP é a falta de tempo para desenvolvê-lo, visto que, é preciso de um tempo maior que no método tradicional, conforme mostram as seguintes expressões:

O método é muito bom, mas precisa de mais tempo para ser aplicado, então acho difícil de ser aplicado durante todo o curso, por isso eu acho que o tradicional é o mais utilizado nos cursos. A gente vive o conflito com outras atividades que precisam ser realizadas e não sobra muito tempo. (E1)

A desvantagem que eu vejo com o método do ABP é que precisa de mais tempo para desenvolver os temas e aí fica apertado para outras tarefas. (E7)

O tempo necessário para o método é muito maior que o modelo tradicional, falta tempo para aplicar em todo curso, penso que poderia ser desenvolvido pelo menos com os temas mais relevantes para a formação de um enfermeiro, isso é priorizar! (E12)

o método é muito bom, mas precisa de mais tempo do que o tradicional, pois a nossa discussão não é superficial e estudamos o que nos interessa naquele momento. (E6)

Os estudantes demonstram em suas falas que o método ABP despende de um tempo maior para ser aplicado quando comparado ao método tradicional, sendo uma das maiores desvantagens na concepção dos estudantes.

\section{DISCUSSÃO}

O método da ABP provoca os estudantes a buscar o conhecimento constantemente e, assim, não ficam esperando do professor as respostas para suas indagações. É um processo de troca mútua de conhecimentos e experiências entre os educandos e o educador/tutor. Neste método, o estudante e o tutor desenvolvem um diálogo educativo e buscam uma direção dos seus conhecimentos para resolver os problemas. Assim sendo, ocorre a mudança, tanto individual, como coletiva, e, consequentemente, a transformação da realidade de uma forma crítica, reflexiva e criativa. ${ }^{4,6}$ 


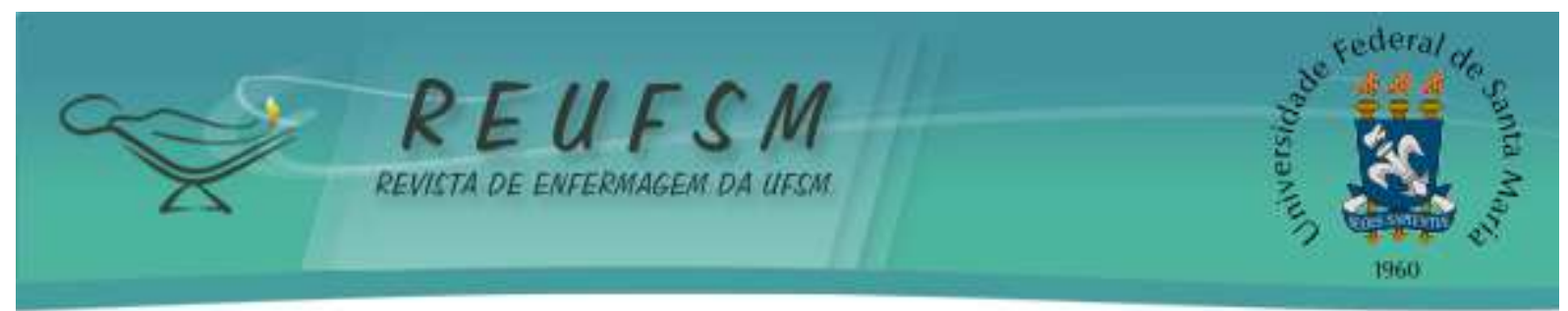

No entanto, no método tradicional, a responsabilidade do processo de ensinoaprendizagem cabe somente ao professor como transmissor de conhecimentos estanques, o qual possui o objetivo de conduzir o estudante e transmitir conhecimento a ele, sendo este apenas um acumulador de informações. ${ }^{16}$

A ABP desenvolve no estudante o interesse pela pesquisa, valoriza a atividade de descobrir, de querer saber sobre algo que ainda não foi identificado e de aprimorar o que já está revelado. Dessa forma, imprime nos estudantes o desenvolvimento de habilidades e atitudes para além das habilidades meramente técnicas. ${ }^{17}$

Em contraponto ao método $\mathrm{ABP}$, o método tradicional não atende às expectativas dos estudantes quanto ao aprendizado. Com esses sendo meros receptores não permitindo críticas nem reflexão, levam o estudante a, somente, memorizar conteúdos para ser avaliado posteriormente. ${ }^{18}$

O aprender por meio da ABP facilita a consolidação de ideias e conhecimentos, ou seja, propicia à aprendizagem significativa do estudante. Tal fato é percebido quando os estudantes começam a questionar uns aos outros sobre temas ou conteúdo de estudo propostos pelo tutor. ${ }^{11}$

Nesse entendimento a teoria da aprendizagem significativa (TAS), proposta por David Ausubel, é caracterizada pela interação dos conhecimento prévios, que devem ser valorizados, e conhecimentos novos, para que assim possa ser construído uma aprendizagem eficaz, propiciando significado real ao conhecimento adquirido, além de expandir sua estrutura cognitiva. ${ }^{19}$

$\mathrm{Na} \mathrm{ABP}$, dentre as inúmeras vantagens para o estudante, uma delas relaciona-se ao favorecimento da aquisição de conhecimentos de forma mais expressiva e duradoura, adquirindo mais conhecimento, com maior rapidez, com maior facilidade de aprendizagem dos conteúdos e com uma visão mais humanista, pois é um ensino orientado para a resolução de problemas, o que, por consequência, leva à interdisciplinaridade, ou seja, aos diversos saberes necessários à solução de um problema. ${ }^{20}$

Em contrassenso, o método tradicional apresenta relação de autoritarismo do docente: aprendizado por memorização, sem participação ativa dos estudantes; o conhecimento é muito limitado; o cronograma é definido e o conteúdo programado, ou seja, não é flexível para que haja modificações durante o processo. ${ }^{21}$

Em um estudo realizado com 120 estudantes de enfermagem taiwaneses, com um grupo experimental e outro controle, verificou-se a efetividade do método ABP. O grupo experimental recebeu uma intervenção com o método ABP e o grupo controle com o não 


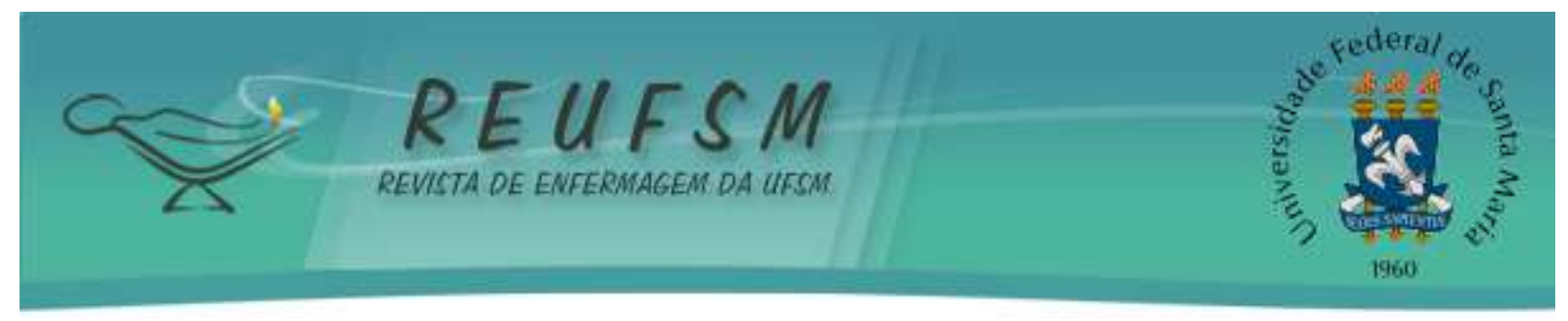

ABP. Demonstrou-se então que o método ABP aumentou o pensamento crítico, a responsabilidade pessoal para autoaprendizagem, a interação do grupo e a capacidade de raciocínio e participação ativa dos estudantes em todas as atividades propostas; resultados que são análogos aos do presente estudo. ${ }^{22}$

Autores afirmam que a metodologia $\mathrm{ABP}$ além de promover nos estudantes o raciocínio científico, também se configura como uma proposta que estimula a aprender e se interessar pela investigação científica, isto é: reconhecer quando é preciso pesquisar, porque é preciso investigar, quais as contribuições, quais as evidências e soluções, argumentar e disseminar os resultados investigados. Desta forma, prepara-se um profissional com competência para modificar o que precisa ser transformado, bem como despertando-o para exercer a cidadania. ${ }^{23}$

Na concepção de autores, outra vantagem do ensino ABP está no fato de estimular o bom relacionamento grupal e destes com o tutor, pois, ao provocar discussões, desenvolve-se a comunicação, na qual se aprende a receber e assimilar críticas como um fator importante para o crescimento, assim, os estudantes perdem o "medo" do tutor e se estabelece um bom relacionamento interpessoal, o que estimula o aprendizado. ${ }^{24}$

Um estudo realizado no Canadá, que envolveu 121 estudantes de enfermagem, que se submeteram a ABP e outros, ao método tradicional, não houve diferença estatisticamente entre os graduandos do método ABP e o método tradicional em relação a competência auto relatada da prática, porém, o estudo identificou que a ABP colabora com diálogos entre o grupo e o tutor, desenvolve laços de ajuda mútua, de colaboração, de amizade e de estímulo, o que promove o desenvolvimento e a prática do bom inter-relacionamento entre todos. ${ }^{25}$

Cabe ressaltar que outro ponto positivo do método ABP consiste no fato de superar a dicotomia existente entre a teoria e prática tão questionada pelos estudantes da área da saúde, em especial, pelos da enfermagem. Este método auxilia na superação desse status quo ao propiciar que o conhecimento adquirido, aprofundado, ampliado e construído tenha sua origem assertiva na prática, no real, no vivido pela pessoa e no percebido por esta como um problema a ser solucionado, ou seja, a teoria está condicionada à prática, pois para que ocorra a teoria é preciso uma relação efetiva com a prática para solucionar os problemas.

Em contrapartida, modelos tradicionais de ensino caracterizam-se: pelo elevado número de estudantes em sala de aula, por apresentarem maior conteúdo teórico em prejuízo da prática; pelo fato de o aprendizado não acontecer segundo realidade social, sendo os 


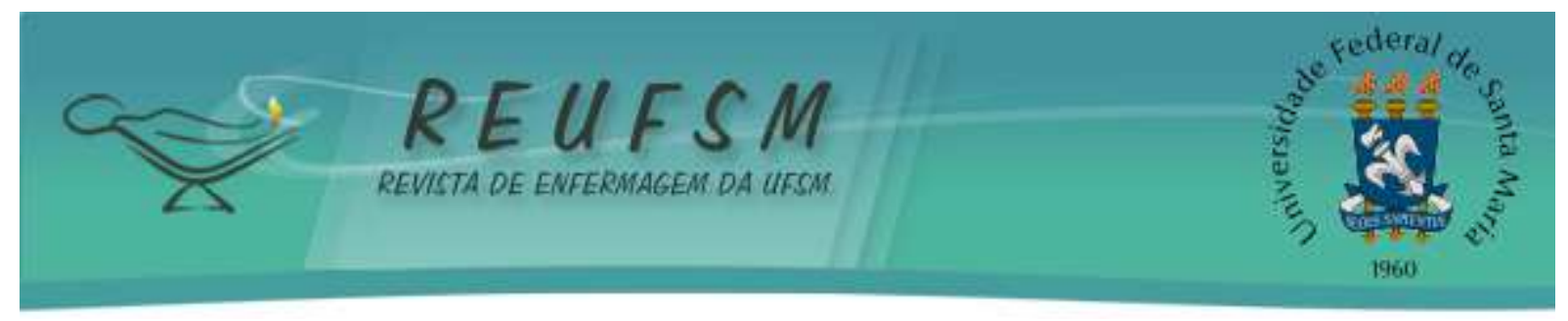

assuntos, ao invés disso, aplicados dentro da subjetividade do docente, o que muitas vezes não corresponde ao necessário, gerando, consequentemente, prejuízo tanto no estágio quanto na vida profissional e falta de integração/interação entre estudantes, docentes, comunidade, prejudicando, assim, a realidade social. ${ }^{21}$

Em estudo realizado com estudantes de enfermagem e medicina em uma universidade do interior do estado São Paulo, os resultados abstraídos das falas indicam que o uso da metodologia ABP contribui para a construção de uma lógica de cuidado holístico, em que há uma relação entre a teoria e a prática, o que é considerado um avanço na formação desses profissionais com relação ao SUS e um atendimento voltado para a realidade da sociedade. ${ }^{26}$

Embora a ABP tenha muitas vantagens, o autor afirma que a gestão de tempo é um desafio a ser enfrentado, visto que necessita de um tempo maior do que as metodologias tradicionais, o que leva, muitas vezes, o estudante a questionar sobre o método devido ao pouco tempo para as outras atividades da vida acadêmica. Entretanto, o tutor que realmente deseja construir um trabalho alternativo, mais libertador, pode utilizar estratégias que facilitam o equacionamento da questão tempo. ${ }^{27}$

Um estudo de implementação da ABP no ensino de Medicina mostrou que, na ótica dos estudantes, o ponto negativo mais mencionado foi o aumento do trabalho e do tempo dedicado à disciplina, a qual foi conflitante com outros compromissos acadêmicos. ${ }^{12}$

Outro estudo realizado em uma pós-graduação em saúde detectou-se, como ponto negativo, a necessidade de maior tempo para a execução das atividades. ${ }^{13}$

\section{CONSIDERAÇÕES FINAIS}

Por meio da presente pesquisa foi possível revelar a percepção dos estudantes de graduação em enfermagem sobre a ABP. Os resultados demonstraram que foi uma estratégia importante no processo ensino-aprendizagem por propiciar amplo conhecimento sobre os temas, despertar o estudante para a pesquisa, facilitar o relacionamento interpessoal e a relação entre teoria e prática. Entretanto, foi identificado o tempo como um fator que limita a execução do método.

Embora os objetivos do estudo tenham sido alcançados, destaca-se alguns fatores limitantes como número pequeno de estudantes de graduação em enfermagem de uma universidade e de apenas um período, impedindo a generalização dos achados. Assim sendo, recomenda-se que outras pesquisas sejam realizadas sobre a temática. 


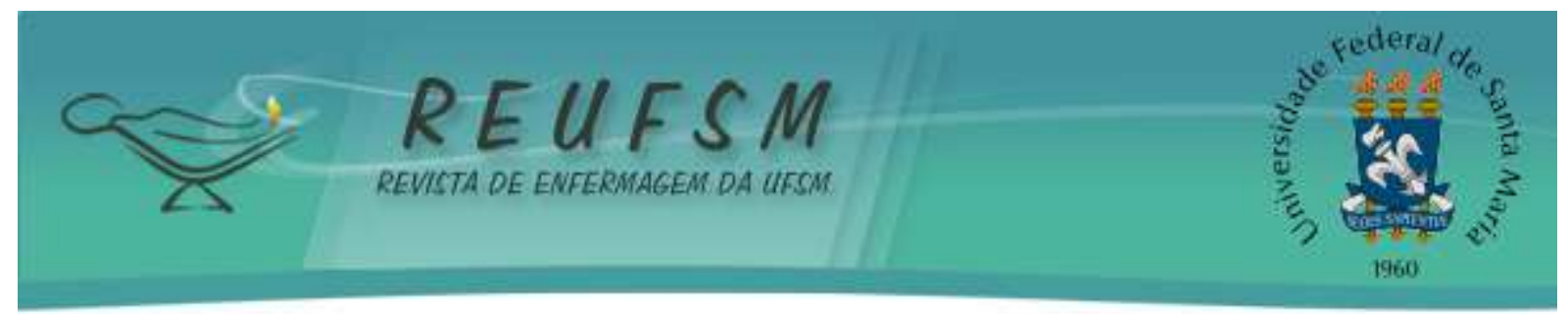

\section{REFERÊNCIAS}

1. Pires AS, Souza NVDO, Penna LHG, Tavares KFA, D'Oliveira CAFB, et al. A formação de enfermagem na graduação: uma revisão integrativa da literatura. Rev Enferm UERJ [Internet]. 2014 [acesso em 30 nov 2016];22(5):705-11. Disponível em: http://dx.doi.org/10.12957/reuerj.2014.11206.

2. Ney MS, Pierantoni CR, Lapão LV. Sistemas de avaliação profissional e contratualização da gestão na Atenção Primária à Saúde em Portugal. Saúde Debate [Internet]. 2015 [acesso em 30 nov 2016] ;39(104):43-55. Disponível em: http://dx.doi.org/10.1590/0103110420151040266.

3. Brasil. Ministério da Educação. Conselho Nacional de educação. Resolução CNE/CES no 3 , de 7 de novembro de 2001. Institui diretrizes curriculares nacionais do curso de graduação em enfermagem. Diário Oficial da União, Brasília (DF); 2001 nov 9. Seção 1, p. 37.

4. Silva RHA, Miguel SS, Teixeira LS. Problematização como método ativo de ensinoaprendizagem: estudantes de farmácia em cenários de prática. Trab Educ Saúde [Internet]. 2011 [acesso em 30 nov 2016];9(1):77-93. Disponível em: http://dx.doi.org/10.1590/S198177462011000100006 .

5. Sobral FR, Campos CJG. Utilização de metodologia ativa no ensino e assistência de enfermagem na produção nacional: revisão integrativa. Rev Esc Enferm USP [Internet]. 2012 [acesso em 30 nov 2016];46(1):208-18. Disponível em: http://dx.doi.org/10.1590/S008062342012000100028 .

6. Staun M, Bergström B, Wadensten B. Evaluation of a PBL strategy in clinical supervision of nursing students: Patient-centred training in student-dedicated treatment rooms. Nurse Educ Today [Internet]. 2010 [acesso em 30 nov 2016];30(7):631-7. Disponível em: https://doi.org/10.1016/j.nedt.2009.12.013.

7. Borochovicius E, Tortella JCB. Aprendizagem Baseada em Problemas: um método de ensino-aprendizagem e suas práticas educativas. Ensaio: Aval Pol Públ Educ [Internet]. 2014 [acesso em 30 nov 2016];22(83):263-94. Disponível em: http://dx.doi.org/10.1590/S010440362014000200002.

8. Mezzari A. O uso da Aprendizagem Baseada em Problemas (ABP) como reforço ao ensino presencial utilizando o ambiente de aprendizagem Moodle. Rev Bras Educ Med [Internet]. 2011 [acesso em 30 nov 2016];35(1):114-21. Disponível em: http://dx.doi.org/10.1590/S0100-55022011000100016.

9. Schmidt HG, Rotgans JI, Yew EH. The process of problem-based learning: what works and why. Med Educ [Internet]. 2011 [acesso em 30 nov 2016];45(8):792-806. Disponível em: https://www.ncbi.nlm.nih.gov/pubmed/21752076.

10. Ribeiro VMB, Ribeiro AMB. A aula e a sala de aula: um espaço- tempo de produção de conhecimento. Rev Col Bras Cir. 2011;38(1):71-6.

11. Mendes MGS, Martins CA, Oliveira C, Silva MJ, Vilaça S. Contributos da aprendizagem baseada em problemas no desempenho do estudante de enfermagem em ensino clínico. Rev Form Innovación Educ Univ [Internet]. 2012 [30 nov 2016];5(4):227-40. Disponível em: http://hdl.handle.net/1822/20513. 


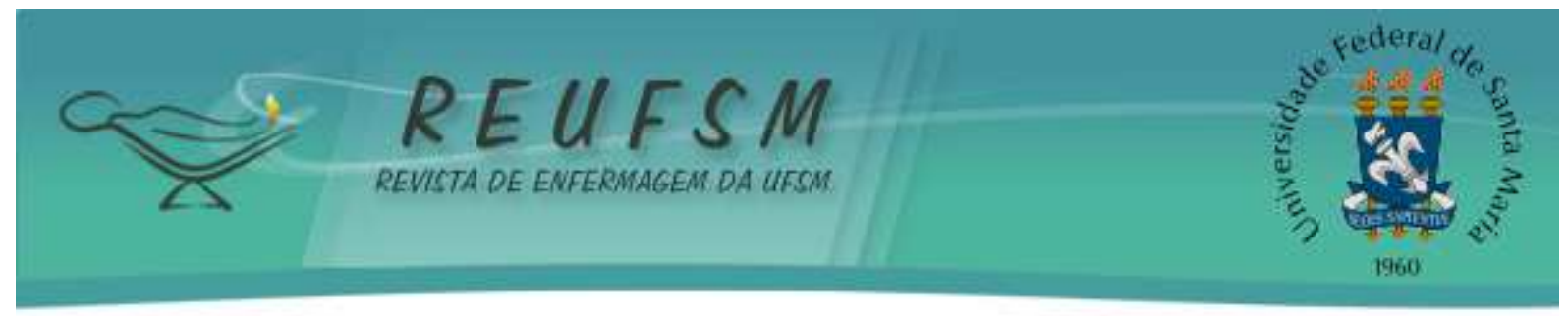

12. Belfor JA, Sena IS, Silva DKB, Lopes BRS, Koga Júnior M, Santos BEF. Competências pedagógicas docentes sob a percepção de alunos de medicina de universidade da Amazônia brasileira. Ciênc Saúde Colet [Internet]. 2018 jan [acesso em 2018 jun 24];23(1):73-82. Disponível em: http://www.scielo.br/scielo.php?script=sci_arttext\&pid=S1413$81232018000100073 \& \operatorname{lng}=$ en.

13. Leal LB, Pereira KLA, Negreiros ALB, Pequeno AMC, Lima GP , Negreiros FDS, et al. Método ativo problematizador como estratégia para formação em saúde. Rev Enferm UFPE. 2018;12(4):1139-43.

14. Faculdade de Medicina de Marília (Famema). Caderno de avaliação: cursos de medicina e enfermagem. Marília: Faculdade de Medicina de Marília; 2015.

15. Bardin L. Análise de conteúdo. São Paulo: Edições 70; 2012.

16. Prado ML, Velho MB, Espíndola DS, Hilda Sobrinho S, Backes VMS. Arco de Charles Maguerez: refletindo estratégias de metodologia ativa na formação de profissionais de saúde. Esc Anna Nery [Internet]. 2012 mar [acesso em 2012 abr 1];16(1):172-7. Disponivel em: http://dx.doi.org/10.1590/S1414-81452012000100023.

17. Costa J, Bechelaine SC, Assis JR. Análise da visão de estudantes e professores sobre a aprendizagem baseada em problemas: uma revisão de literatura. Rev Mim Educ Fis. 2010;(5):294-303.

18. Alencar NA, Sousa Junior JV. Aprendizagem baseada em problemas: uma nova referência para a construção do currículo de cursos da área de saúde. Rev Intefaces [Internet]. 2013 [acesso em 2013 mar 18];1(1). Disponível em: http://interfaces.leaosampaio.edu.br/arquivos/template-artigo.pdf?download=1.

19. Ausubel DP. The psychology of meaningful verbal learning. New York: Grune \& Stratton; 1963.

20. Cruz JA, Wiemes L. Incentivo à melhoria de prátivas pedagógicas com a utilização do Método PBL. Conhecimento Interativo. 2014;8(2):87-101.

21. Souza CS, Iglesias AG, Pazin-Filho A. Estratégias inovadoras para métodos de ensino tradicionais - aspectos gerais. Medicina (Ribeirão Preto). 2014;47(3):284-92.

22. Tseng HC, Chou FH, Wang HH, Ko HK, Jian SY, Weng WC. The effectiveness of problem-based learning and concept mapping among Taiwanese registered nursing students. Nurse Educ Today [Internet]. 2011 [acesso em 30 nov 2016];31(8):e41-e46. Disponível em: https://www.sciencedirect.com/science/article/pii/S0260691710002467?via\%3Dihub.

23. Vasconcelos C, Almeida A. Aprendizagem baseada na resolução de problemas no ensino das ciências: propostas de trabalho para ciências naturais, biologia e geologia. Porto: Porto Editora; 2012.

24. Paranhos VD, Mendes MMR. Currículo por competência e metodologia ativa: percepção de estudantes de enfermagem. Rev Latinoam Enferm [Internet]. 2010 [acesso em 30 nov 2016];18(1):109-15. Disponível: http://dx.doi.org/10.1590/S0104-11692010000100017.

25. Applin H, Williams B, Day R, Buro K. A comparison of competencies between problembased learning and non-problem-based graduate nurses. Nurse Educ Today [Internet]. 2011 


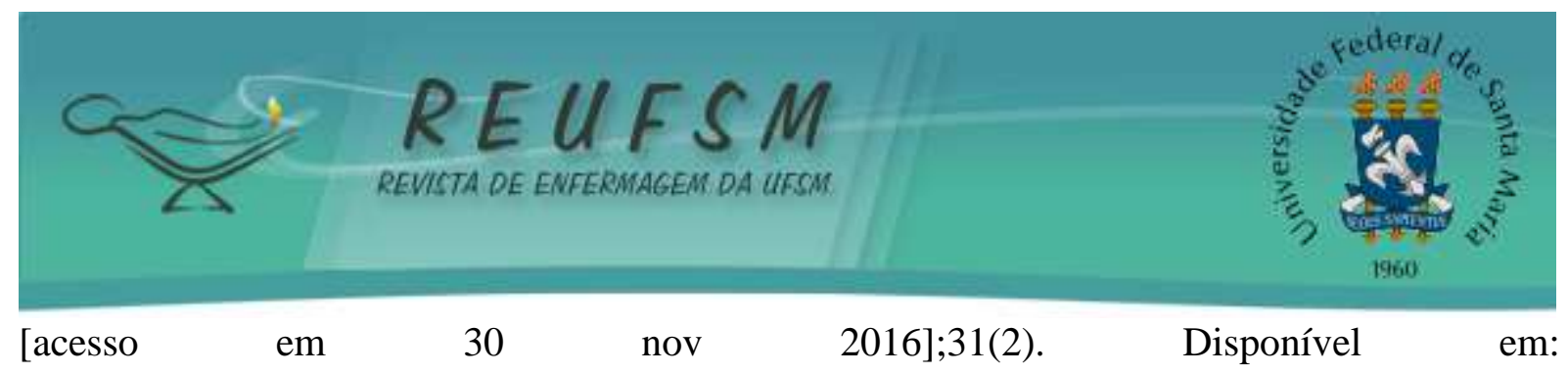
https://www.ncbi.nlm.nih.gov/pubmed/20817332.

26. Marin MJS, Lima EFG, Paviotti AB, Matsuyama DT, Silva LKD, Gonzalez C, et al. Aspectos das fortalezas e fragilidades no uso das metodologias ativas de aprendizagem. Rev bras educ med. 2010 [acesso em 30 nov 2016];34(1):13-20. Disponível em: http://dx.doi.org/10.1590/S0100-55022010000100003.

27. Vasconcellos CS. Planejamento: projeto de ensino-aprendizagem e projeto políticopedagógico. São Paulo: Libertad; 2005. p. 118-20.

Data de submissão: 04/07/2017

Data de aceite: 03/08/2018

Autor correspondente: Miriam Fernanda Sanches Alarcon

E-mail: miriam@uenp.edu.br

Endereço: Pós-Graduação em Enfermagem. Av. Prof. Rubens Guimarães Montenegro, S/N, Botucatu, SP.

CEP: 18618-687 